February 2000 - NREL/CP-500-27510

\title{
Determining Equivalent Damage Loading for Full-Scale Wind Turbine Blade Fatigue Tests
}

G. Freebury

G. Edward Engineering

W. Musial

National Renewable Energy Laboratory

Presented at the $19^{\text {th }}$ American Society of Mechanical Engineers (ASME) Wind Energy Symposium Reno, Nevada January 10-13, 2000

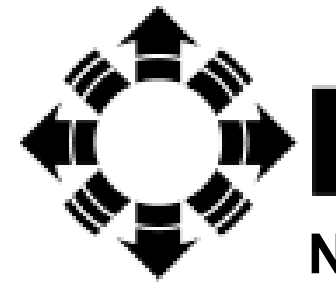

\section{NPE}

National Renewable Energy Laboratory

1617 Cole Boulevard

Golden, Colorado 80401-3393

NREL is a U.S. Department of Energy Laboratory

Operated by Midwest Research Institute $\bullet$ Battelle $\bullet$ Bechtel

Contract No. DE-AC36-99-G010337 


\section{NOTICE}

The submitted manuscript has been offered by an employee of the Midwest Research Institute (MRI), a contractor of the US Government under Contract No. DE-AC36-99G010337. Accordingly, the US Government and MRI retain a nonexclusive royalty-free license to publish or reproduce the published form of this contribution, or allow others to do so, for US Government purposes.

This report was prepared as an account of work sponsored by an agency of the United States government. Neither the United States government nor any agency thereof, nor any of their employees, makes any warranty, express or implied, or assumes any legal liability or responsibility for the accuracy, completeness, or usefulness of any information, apparatus, product, or process disclosed, or represents that its use would not infringe privately owned rights. Reference herein to any specific commercial product, process, or service by trade name, trademark, manufacturer, or otherwise does not necessarily constitute or imply its endorsement, recommendation, or favoring by the United States government or any agency thereof. The views and opinions of authors expressed herein do not necessarily state or reflect those of the United States government or any agency thereof.

Available electronically at http://www.doe.gov/bridge

Available for a processing fee to U.S. Department of Energy and its contractors, in paper, from:

U.S. Department of Energy

Office of Scientific and Technical Information

P.O. Box 62

Oak Ridge, TN 37831-0062

phone: 865.576 .8401

fax: 865.576.5728

email: reports@adonis.osti.gov

Available for sale to the public, in paper, from:

U.S. Department of Commerce

National Technical Information Service

5285 Port Royal Road

Springfield, VA 22161

phone: 800.553 .6847

fax: 703.605.6900

email: orders@ntis.fedworld.gov

online ordering: http://www.ntis.gov/ordering.htm

Printed on paper containing at least $50 \%$ wastepaper, including $20 \%$ postconsumer waste 


\title{
DETERMINING EQUIVALENT DAMAGE LOADING FOR FULL-SCALE WIND TURBINE BLADE FATIGUE TESTS
}

\author{
Gregg Freebury \\ G. Edward Engineering \\ Lafayette, $\mathrm{CO}$ \\ Walter Musial \\ National Renewable Energy Laboratory \\ Golden, $\mathrm{CO}$
}

\begin{abstract}
This paper describes a simplified method for converting wind turbine rotor design loads into equivalent-damage, constant-amplitude loads and load ratios for both flap and lead-lag directions. It is an iterative method that was developed at the National Renewable Energy Laboratory (NREL) using PalmgrenMiner's linear damage principles. The general method is unique because it does not presume that any information about the materials or blade structural properties is precisely known. According to this method, the loads are never converted to stresses. Instead, a family of M-N curves (moment vs. cycles) is defined with reasonable boundaries for load-amplitude and slope. An optimization program iterates and converges on the constant amplitude test load and load ratio that minimizes the sensitivity to the range of M-N curves for each blade section.
\end{abstract}

We constrained the general method to match the NedWind 25 design condition for the Standards, Measurements, and Testing (SMT) blade testing program. SMT participants agreed to use the fixed S-N slope of $m=10$ from the original design to produce consistent test-loads among the laboratories. Unconstrained, the general method suggests that slightly higher test loads should be used for the NedWind 25 blade design spectrum. NedWind 25 blade test loads were computed for lead-lag and flap under single-axis and two-axis loading.

\section{INTRODUCTION}

The objective of load-based blade fatigue tests is to verify that the as-built blade structure is capable of sustaining the full spectrum of loads it will experience during its life. A typical wind turbine load spectrum may consist of more than 500 million load cycles occurring over a wide range of load ratios. (The load

This material is declared a work of the U.S. Government and is not subject to copyright protection in the United States. ratio, $\mathrm{R}$, is the minimum load in one load cycle divided by the maximum load in one load cycle). Because of practical limitations, laboratories cannot test a blade with such a large number of design-load cycles in a time period that is reasonable. The advantage of laboratory testing is that the load-amplitude may be increased to accelerate the level of damage per load cycle by as much as two orders of magnitude over the design condition in order to achieve the same total damage in a fraction of the time. This analysis is routinely executed by applying linear damage models such as Miner's Rule. The difficulty comes in knowing the properties of the structure well enough to predict where the high damage will occur.

Most methods convert loads to stresses at several spanwise blade sections. Then, for measured or assumed S-N curves (applied stress versus allowable cycles to failure) of the laminate, Miner's Rule is applied to determine the design damage. Equivalentdamage test loads are then computed for given test load ratios and number of load cycles. These methods determine test loads by assuming that the behavior of the test article matches the design condition exactly. If the test blade is different than the design, then significant uncertainty is introduced. For example:

1. The test blade cross-section geometry will not exactly match the drawing.

2. Blade laminate material properties will deviate from coupon properties (e.g. resin versus fiber rich, ply drops, material handling, and workmanship).

3. The critical section may be in a bolted or bonded joint or in a stress concentration region that will have a unique $\mathrm{S}-\mathrm{N}$ curve.

As a result of these variations, damage to the test blade will be evaluated either higher or lower than its actual value and may disguise a problem where high damage is sustained. Moreover, considerable time is spent calculating and applying the various blade properties at each step of the analysis. This adds unnecessary 
complexity to the problem and exposes the analysis to possible accounting errors.

\section{SMT PROGRAM}

\section{Background}

The SMT program was initiated in 1996 in Europe under the Joule III Program to help blade-testing laboratories harmonize their testing methods and help develop a standard set of blade testing procedures. Three European member countries and the United States participated in this project, represented by five laboratories including RIS $\varnothing$ (Denmark), CRES (Greece), Delft (Netherlands), ECN (Netherlands) and NREL (USA). NREL was an invited member of this project and its participation was self-funded. However, NREL completed all the requirements of the project and participated as an equal partner.

The SMT program objectives were to make a reference database for different test methods, techniques, and results of static and fatigue testing of wind turbine blades being used by different laboratories, and to bring the international laboratories closer to a unified approach.

Since NREL began blade testing in 1990 we have tested more than 75 wind turbine blades; however, most of this work was proprietary and is not usually available in the public domain. This has inhibited the development and dissemination of NREL testing methods. The SMT program gave NREL an opportunity to share the test results and methods amongst the project partners and with the wind industry at large.

\section{Program Elements}

The SMT blade-testing program consisted of compulsory property measurements, static strain verification testing, and fatigue testing. This paper covers only the methodology used in developing the fatigue test-loads. A more comprehensive description of the test program and the NREL results is given in Reference 1.

The SMT program selected a commercial blade model with good design records that could be released to the SMT laboratories. The project coordinators took a sample population from series production and randomly assigned the blades to each of the participating laboratories. CRES and NREL agreed to test two blades while the other laboratories performed their tests on one blade. Having two blades allowed NREL to compare two different fatigue-testing methods: singleaxis-combined loading and two-axis loading.
Test Blade Description

The NedWind 25, 12-meter (m) blade was chosen testing. Rotorline (now part of LM Glasfiber) in the Netherlands manufactured the blade. The blades are $12-\mathrm{m}$ in length and are constructed from glass fiber reinforced plastic. Each blade has a single sandwich panel spar running from $13 \%$ to $83 \%$ of blade span at $40 \%$ chord and is constructed with high-strength laminates at the root and at the panels surrounding the blade spar. Lower-strength material is used on the leading and trailing edges. The blade hub attachment is a steel flange that clamps with radial bolts around the blade root.

Rotorline and NedWind provided blade structural and design load information to the project laboratories including a complete set of 100 design-load cases at 10 spanwise blade stations. Stations 1 through 3 are inboard of the root flange and were ignored for this analysis. The outer seven stations were used in the analysis. Station 4 corresponds to the root flange interface.

For each load case, the number of cycles was given for three principal loads: flap moment, lead-lag moment, and axial forces. These loads were given for both the mean and the alternating component. The design documents included a complete description of the design including design load, material, and stress concentration factors used for the static and fatigue analysis. The fatigue analysis also gave theoretical design damage values at many points over the blade planform.

Test-Load Factors

To minimize the variability among the laboratories, the project laboratories agreed to use the same interpretations for the load factors when scaling the design load spectrum. In addition, we agreed to adhere to the prescriptive portions of IEC $61400-23 .^{2}$ In addition to the design-load factors applied by NedWind, the following test load factors were applied by all the labs to the design loads.

Table 1 - Fatigue Test Load Factors Used

\begin{tabular}{ll}
\hline Test-Load Factors & Value \\
\hline Wind Farm Turbulence & 1.04 \\
Blade-to-Blade Variations & 1.10 \\
Fatigue Formulation Uncertainty & 1.05 \\
\hline
\end{tabular}


Material Properties

The NedWind test blade, like most wind turbine rotor blades, is made of fiberglass. The designers assumed a generalized S-N fatigue slope for this blade of $\mathrm{m}=10$, which is a widely used value for good performance on a basic unidirectional laminate. ${ }^{3}$ The original NedWind 25 design analysis used a Goodman relationship that was linear-symmetric about an offset to the right of the $\mathrm{R}=-1.0$ line.

As part of the SMT program, the laboratories agreed to adhere to the major design assumptions to reduce the variability in the final test results. Therefore, NREL constrained the analysis to the $\mathrm{S}-\mathrm{N}$ fatigue slope of $\mathrm{m}=$ 10. For the Goodman relation, we modified the original NedWind 25 design slightly without a significant impact on the results. This modification is explained in more detail later in this paper. From experience, however, we know that these S-N fatigue properties do not represent the details of the blade where failure is likely. In fact, the exact $\mathrm{S}-\mathrm{N}$ properties of the actual failure locations are often unknown to the designers and are very difficult to determine because the failures tend to occur in joints, bonds, or substructural details that are difficult to characterize. This proved to be true for this test as well.

\section{SIMPLIFIED LOAD SPECTRUM-BASED} METHOD

\section{Conventional Test-Load Methods}

Using conventional analyses, equivalent test loads are typically based on the blade structural design. ${ }^{4}$ These methods usually require a complex and time consuming strength analysis, as well as a thorough understanding of the fatigue performance of the blade. As outlined in the introduction, many errors can be propagated through this process. Blade test standards attempt to compensate for these potential errors by applying significant load factors to the equivalent damage test loads.

One of the goals of the SMT program at NREL was to simplify the fatigue test-load derivation process and minimize the potential errors in the analysis. It appeared that the best method would be to derive the fatigue test loads in a way analogous to the determination of ultimate-strength loads. Recall that the ultimate-strength loads are simply extracted from the load spectrum. The peak load in the spectrum is applied to the blade to verify proper static strength. It is not necessary to know the blade geometry and material properties and perform a complete stress analysis.

Simplified Load Spectrum Method

The goal of the simplified load spectrum method is to derive an equivalent damage fatigue test that is only dependent on the design-load spectrum. Using this method, the test loads are derived assuming the blade geometry and material fatigue properties are not accurately known. Then the test article is allowed to (and probably does) deviate from the intended design without affecting the test conditions.

This method remains strictly in the load domain; therefore there is no conversion to stresses. So instead of an S-N curve there will be an M-N curve (applied moment vs. allowable cycles to failure) for the blade. The curve will be defined by the relationship,

$$
\mathrm{Ma}=\mathrm{Mu} \times \mathrm{N}^{(-1 / \mathrm{m})}
$$

$\begin{array}{ll}\text { Where, } & \\ \mathrm{Ma} & \text { Amplitude moment in one load cycle } \\ \mathrm{Mu} & \text { Ultimate moment of the blade } \\ \mathrm{N} & \text { Allowable cycles to failure } \\ \mathrm{m} & \text { Slope of the curve }\end{array}$

A blade's fatigue failure can occur in many locations by various modes e.g., skin laminate failure in tension or local buckling, adhesive failure in shear or peel, or bolted joint failure. Each failure mode could be characterized by a different $\mathrm{M}-\mathrm{N}$ curve. A family of curves was defined to bound the potential $\mathrm{M}-\mathrm{N}$ combinations for the test blade. A range of ultimate moments from $1.5 \times \mathrm{M}_{\max }$ to $4.5 \times \mathrm{M}_{\max }$ and a range of slopes from $\mathrm{m}=6$ to $\mathrm{m}=12$ were used. $\mathrm{M}_{\max }$ is the maximum characteristic moment in the NedWind 25 load spectrum. The $1.5 \times \mathrm{M}_{\max }$ was selected for the lower bound curve, which matched the $100 \%$ extreme static test level and the extreme design limit load. The 4.5 factor was arbitrarily selected for the higher bound to account for conservative designs. Implicit in these boundaries is the assumption that the ultimate moment to cause blade failure is somewhere between 1.5 and 4.5 times the maximum load case experienced by the blade on the NedWind 25 turbine. 


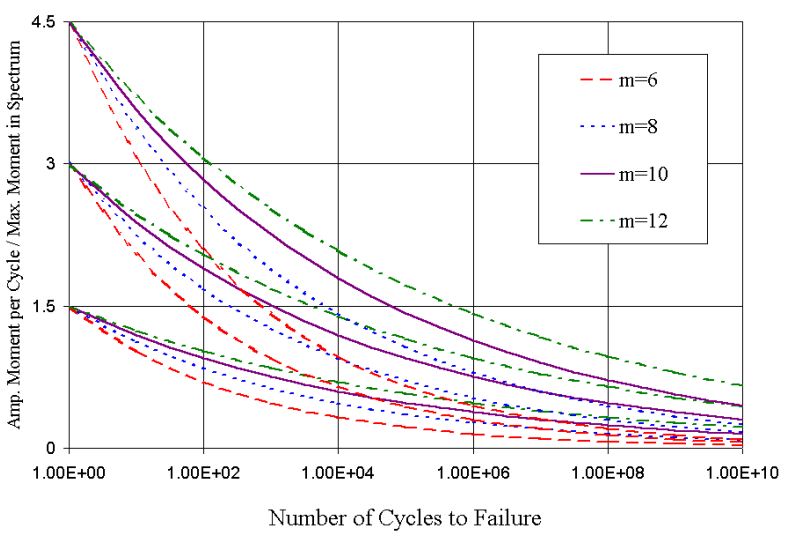

Figure 1. $M-N$ curve family at $R=-\mathbf{1 . 0}$

The range of slopes from 6 to 12 was supported by an extensive database of fiberglass laminates. ${ }^{3}$ Slopes approaching 6 were seen in poor performing fabrics and laminates, as well as in better-performing laminates with fabrication flaws such as resin- and fiber-rich areas, ply drops, and complex geometry. The family of $\mathrm{M}-\mathrm{N}$ curves is shown in Figure 1.

Note that three levels of moments $\left(1.5 \times \mathrm{M}_{\max }, 3.0 \mathrm{x}\right.$ $\mathrm{M}_{\max }$, and $4.5 \mathrm{x} \mathrm{M}_{\max }$ ) were selected for this analysis and four M-N slopes $(\mathrm{m}=6, \mathrm{~m}=8, \mathrm{~m}=10$, and $\mathrm{m}=12)$ giving a total of 12 curves. Using more curves to gain better resolution in the analysis was examined; however, it had very little effect on the results.

The damage associated with each curve can be calculated by applying Palmgren-Miner's Rule as follows:

$$
\text { Damage }=\sum_{\mathrm{i}=1}^{\mathrm{j}} \frac{\mathrm{n}_{\mathrm{i}}}{\mathrm{N}_{\mathrm{i}}}
$$
where,

$\begin{array}{ll}\mathrm{i} & \text { Load case number } \\ \mathrm{j} & \text { Total number of load cases } \\ \mathrm{n}_{\mathrm{i}} & \text { Number of load cycles for case } \mathrm{i} \\ \mathrm{N}_{\mathrm{i}} & \begin{array}{l}\text { Number of load cycles to failure for } \\ \text { case } \mathrm{i} .\end{array}\end{array}$

The family of M-N curves defined above are set at a load ratio of $\mathrm{R}=-1.0$. The Goodman relationship was also assumed to be linear as far as the $R=-1.0$ line. Because all but 1 of the 100 NedWind 25 load cases are on or to the right (positive mean load) of the $\mathrm{R}=-1.0$ line, it was only necessary for us to model the right half of the Goodman diagram as shown in Figure 2. The one case on the left side of the $\mathrm{R}=-1.0$ line is a relatively low-damage case; modifying the method to account for this case had a negligible effect.

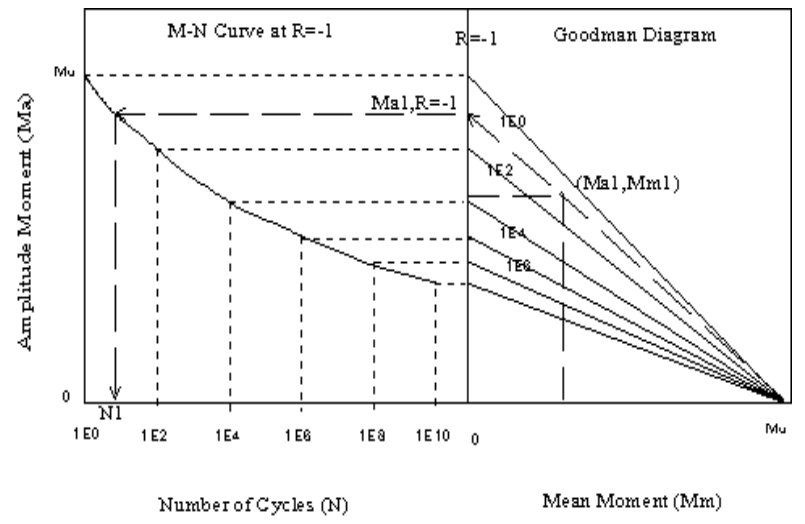

Figure 2. Goodman diagram and sample load case

For simplicity, we proceeded with the right half of the Goodman diagram model. When looking at different fatigue failure mechanisms, this linearized Goodman model combined with the M-N family of curves appears to be a good representation of the NedWind 25 design. If the blade's fatigue failure were to occur in a fiberglass laminate, one would expect that the M-N curve and Goodman diagram of the blade would be best characterized by the laminate's S-N curve and Goodman diagram. A blade in bending will have skin laminates in both tension and compression. S-N curves for compressive failure in laminates tend to have a lower ultimate stress and a higher slope than their tensile counterparts ${ }^{3}$. The ratio of a tensile to a compressive ultimate stress can approach 2.0. This creates a wide range of laminate material properties, but they should be well bounded by the assumed M-N curves. The laminate compression curves may be most closely characterized by the $1.5 \times \mathrm{M}_{\max }, \mathrm{m}=10-12$ curves whereas the tension curves may better match the $4.5 \times \mathrm{M}_{\max }, \mathrm{m}=6-10$ curves.

To support our linear Goodman model, another point should be made concerning the transition from a tensile to a compressive fatigue failure in a fiberglass laminate. At low cycles (typically below 1,000), the transition is somewhere between $\mathrm{R}=0.1$ and $\mathrm{R}=-1.0$. At higher cycles, the transition is closer to $R=-1.0$ and may even trend towards $\mathrm{R}=-2.0$ as the cycles increase ${ }^{3}$. This produces a nonlinear Goodman diagram. The impact of this was evaluated for the NedWind 25 spectrum. When this spectrum was plotted onto a normalized Goodman diagram for a similar laminate from the Montana State University (MSU)/U.S. Department of Energy (DOE) fatigue database, the linear representation appeared to be the best fit. ${ }^{3}$ 
It is also necessary to point out that the original NedWind 25 design analysis used a Goodman relationship that was linear-symmetric about an offset to the right of the $\mathrm{R}=-1.0$ line. This offset truncated the tensile failure line creating a lower peak amplitude at the tensile-to-compressive-fatigue-failure transition point. This relationship was compared with the simplified load spectrum-based method presented in this paper. The difference between the SMT program's offset linear model and the $\mathrm{R}=-1.0$ linear model was negligible $(0.2 \%)$.

Most of the above discussion assumes that the failure occurs in the laminates where good coupon data can be collected. If the blade fatigue failure occurs in a structural detail such as a bonded or bolted joint, a Goodman relationship for the blade would be characterized by the Goodman relationship for that joint. Unfortunately, Goodman diagrams for joints are difficult to define because there is almost no joint fatigue data available and the number of test variables is greatly increased over coupon testing. For lack of a better model, we considered our $\mathrm{R}=-1.0$ linear Goodman relationship reasonable for characterizing joint failures.

The $\mathrm{R}=-1.0$ linear Goodman relationship also simplifies the calculations and is easier to understand in this initial application of the method. However, this method can be applied to any nonlinear Goodman relationship by modifying the extrapolation routines that will now be discussed.

Because the load cases in the fatigue spectrum are at various load ratios, the equivalent damage will have to be extrapolated using a Goodman diagram. Each case in the load spectrum is defined with a moment amplitude, moment mean, and number of cycles. A sample load case is shown in Figure 2 and called load case 1 .

The value for the amplitude mean when $\mathrm{R}=-1.0$ $\left(\mathrm{M}_{\mathrm{a} 1, \mathrm{R}=1}\right)$, is extrapolated by setting the slopes on the Goodman diagram equal (see Figure 2).

$$
\frac{\mathrm{Ma}_{1, \mathrm{R}=-1}}{\mathrm{Mu}}=\frac{\mathrm{Ma}_{1}}{\mathrm{Mu}-\mathrm{Mm}_{1}}
$$

Solving for $\mathrm{Ma}_{1, \mathrm{R}=-1}$,

$$
\mathrm{Ma}_{1, \mathrm{R}=-1}=\frac{\mathrm{MuMa}_{1}}{\mathrm{Mu}-\mathrm{Mm}_{1}}
$$

Plugging Equation 4 into Equation 1 and solving for the allowable number of cycles to failure for load case 1 gives,

$$
\mathrm{N}_{1}=\left(\frac{\left(\mathrm{Mu}-\mathrm{Mm}_{1}\right)}{\mathrm{Ma}_{1}}\right)^{\mathrm{m}}
$$

The damage from load case 1 is simply $D_{1}=\frac{n_{1}}{N_{1}}$.

Summing the damage from all the load cases will give the total damage, $D_{\text {total }}=\sum_{i} \frac{n_{i}}{N_{i}}$.

To get the equivalent damage test-load, the test conditions must be specified. Typically, this means the test load ratio, $R_{t}$, and number of cycles, $n_{t}$. Because the total damage, $D_{t}, R_{t}$, and $n_{t}$ are known, the test amplitude load and mean load can be calculated. This can be shown again with an example in Figure 3 below. For this case, it is assumed that the test load ratio is 0.1 and the test cycles are $3 \times 10^{6}$.

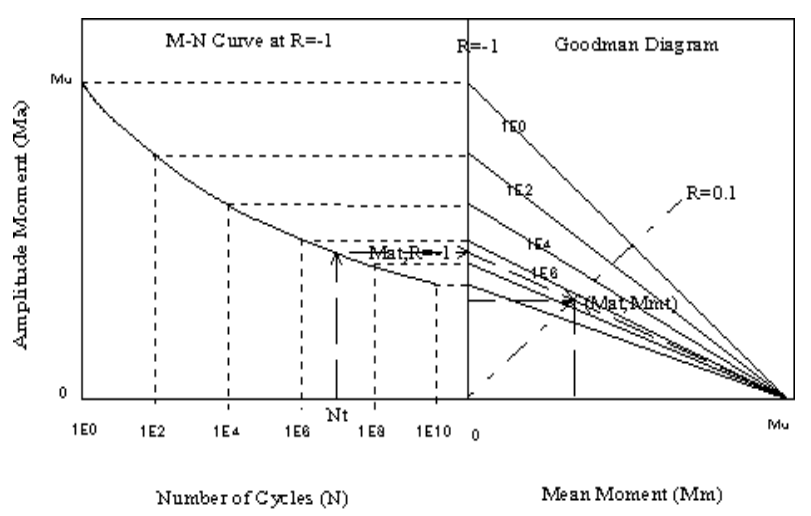

Figure 3. Derivation of equivalent-damage test load

The first step is to calculate the total number of allowable cycles to give the same total damage when the $3 \times 10^{6}$ test cycles are applied.

$$
\begin{aligned}
& \mathrm{D}_{\text {total }}=\frac{\mathrm{n}_{\mathrm{t}}}{\mathrm{N}_{\mathrm{t}}} \\
& \mathrm{N}_{\mathrm{t}}=\frac{\mathrm{n}_{\mathrm{t}}}{\mathrm{D}_{\text {total }}}
\end{aligned}
$$


Where,

$\mathrm{n}_{\mathrm{t}} \quad$ Number of test cycles

$\mathrm{N}_{t} \quad$ Number of allowable cycles to failure at test loads.

From Equation 1,

$$
\mathrm{Ma}_{\mathrm{t}, \mathrm{R}=-1}=\mathrm{Mu} \times \mathrm{N}_{\mathrm{t}}{ }^{(-1 / \mathrm{m})} .
$$

Again setting the slopes equal,

$$
\frac{\mathrm{Ma}_{\mathrm{t}, \mathrm{R}=-1}}{\mathrm{Mu}}=\frac{\mathrm{Ma}_{\mathrm{t}}}{\mathrm{Mu}-\mathrm{Mm}_{\mathrm{t}}} .
$$

Defining the load ratio in terms of mean and amplitude moments,

$$
\mathrm{R}=\frac{\mathrm{M} \text { min,1cycle }}{\mathrm{M} \text { max,lcycle }}=\frac{\mathrm{Mm}-\mathrm{Ma}}{\mathrm{Mm}+\mathrm{Ma}}
$$

Mmin,1cycle Minimum moment in one load cycle Mmax,1cycle Maximum moment in one load cycle

From Equation 10, the mean test moment is,

$$
\mathrm{Mm}_{\mathrm{t}}=\mathrm{Ma}_{\mathrm{t}}\left(\frac{1+\mathrm{R}_{\mathrm{t}}}{1-\mathrm{R}_{\mathrm{t}}}\right)
$$

Combining Equations 9 and 11 and solving for $\mathrm{Ma}_{\mathrm{t}}$.

$$
M a_{t}=\frac{M u}{\frac{M u}{M a_{t, R=-1}}+\left(\frac{1+R_{t}}{1-R_{t}}\right)}
$$

Plugging Equation 8 into 12 gives $\mathrm{Ma}_{\mathrm{t}}$ in terms of $\mathrm{N}_{\mathrm{t}}$, $\mathrm{Mu}$, and $\mathrm{R}_{\mathrm{t}}$.

$$
\mathrm{Ma}_{\mathrm{t}}=\frac{\mathrm{Mu}}{\mathrm{N}_{\mathrm{t}}{ }^{1 / \mathrm{m}}+\frac{1+\mathrm{R}_{\mathrm{t}}}{1-\mathrm{R}_{\mathrm{t}}}}
$$

Adding Equation 7 into 13 gives $\mathrm{Ma}_{\mathrm{t}}$ in terms of $\mathrm{D}_{\text {total }}$, $\mathrm{n}_{\mathrm{t}}, \mathrm{Mu}$, and $\mathrm{R}_{\mathrm{t}}$.

$$
\mathrm{Ma}_{\mathrm{t}}=\frac{\mathrm{Mu}}{\left(\frac{\mathrm{n}_{\mathrm{t}}}{\mathrm{D}_{\text {total }}}\right)^{(1 / \mathrm{m})}+\frac{1+\mathrm{R}_{\mathrm{t}}}{1-\mathrm{R}_{\mathrm{t}}}}
$$

The mean and the amplitude of the test load can now be calculated for any test-load ratio, number of test cycles, and defined M-N curve using Equations 11 and 14.

The next step was to apply an interpolation routine to find the optimum test-load ratio that minimized the sensitivity of the test loads to the family of M-N curves. A macro was written using Microsoft Excel's solver. The solver varied $R_{t}$ to find the minimum range in maximum test loads $\left(\mathrm{Ma}_{\mathrm{t}}+\mathrm{Mm}_{\mathrm{t}}\right)$. In other words, for any given $\mathrm{R}_{\mathrm{t}}$, there are 12 calculated test loads that correspond to the $12 \mathrm{M}-\mathrm{N}$ curves shown in Figure 1. The solver finds the $\mathrm{R}_{\mathrm{t}}$ where the spread in the 12 test loads is at a minimum.

The above steps were done at each blade station along the span for both flap and lead-lag bending.

\section{APPLICATION TO NEDWIND 25 BLADE}

The NedWind 25 load spectrum data are shown in Figures 4 and 5 at blade Station 5 for both flap and lead-lag moments. Blade Station 5 is at 2.65 meters from the center of rotation. The 100 design load cases are presented as open, square symbols. Figures 4 and 5 also show the calculated equivalent damage Goodman diagram curves for blade Station 5 in flap and lead-lag directions. There are 12 equivalent damage curves that correspond to the family of M-N curves for $3 \times 10^{6}$ test cycles. The Figure 3 example shows how each curve was generated. Since the NedWind 25 load spectrum was applied to 12 unique M-N curves, there were 12 different fatigue damage totals. So, each Goodman curve in Figures 4 and 5 shows the mean and amplitude test moments that will give the equivalent damage for the corresponding M-N curve at 3 million test cycles. In other words, any point along each Goodman curve gives the same damage total for 3 million test cycles as any other point on the same curve, but a different damage total from any point on any other curve. Note the mean and amplitude moments in Figures 4 and 5 have again been normalized to the maximum moment in the load spectrum.

The figures also show the optimized test load ratio $\left(R_{t}\right)$ line. Note that, graphically, this radial line intersects the 12 equivalent-damage test-load curves at the point of minimum scatter. These intersections are shown as closed diamond symbols. These figures also show that there is clearly an optimum $R_{t}$ where possible errors in $\mathrm{S}-\mathrm{N}$ slopes are minimized. It also shows how great the potential errors can be if $R_{t}$ is arbitrarily selected. For example, if a non-optimum $R_{t}$ was selected in Figure 4, at say $\mathrm{R}=0.5$, and the $\mathrm{S}-\mathrm{N}$ slope was not accurately 
known, a very wide range of possible test loads will be given.

For the NedWind 25 spectrum, the scatter across the equivalent damage test loads at the $\mathrm{R}_{\mathrm{t}}$ is especially tight in the flap direction. This indicates that at the optimum $R_{t}$ of 0.081 , the errors associated with choosing the wrong M-N slope are lowest. For the lead-lag loads in Figure 5, the scatter is lowest at $R_{t}=-0.61$, but a wider scatter band is indicated.

The figures also show that the optimized $R_{t}$ lines up quite well with the load ratios of the individual load cases in the spectrum. Intuitively, it makes sense that the optimum $R_{t}$ would correspond with the load spectrum.

The final SMT program test loads at each station were taken from the maximum of the three remaining $\mathrm{M}-\mathrm{N}$ curves corresponding to $\mathrm{S}-\mathrm{N}$ slopes of $\mathrm{m}=10$ at the optimized $R_{t}$. In the flap direction, the difference in possible test-loads was insignificant for the NedWind 25 load spectrum because the scatter was so close. It can be seen from Figure 5 that if just the $m=10$ curves are considered, the lead-lag scatter significantly improves because the optimum $\mathrm{R}_{\mathrm{t}}$ value shifts slightly to the right and any deviations with ultimate moment can also be ignored.

When the full range of slopes are included for the unconstrained case, the greater scatter at the optimum $R_{t}$ would suggest slightly higher edge moments, leaving the final loads open to some interpretation. The final load would depend on how conservative the test needed to be and how much confidence the designer had in the fatigue formulation. Because many wind turbine blades have structural details with unknown or poorly understood material properties, the higher loads corresponding to $\mathrm{m}=6$ would be recommended.

\section{NREL TEST LOADS}

Station 5 loads were chosen to illustrate the method in Figures 4 and 5 because it represents one of the most critical sections of the blade. However, the same analysis was performed for all the relevant blade sections. The results of this analysis applied for all the blade stations are shown in Figures 6 and 7.

As stated earlier, the NedWind 25 blade used an S-N material fatigue slope of $\mathrm{m}=10$ during the design. Because the SMT program laboratories agreed to use the same assumptions in the test as were used in the design, the data shown are the $\mathrm{m}=10$ points for the optimized $R_{t}$ values.
Figures 6 and 7 also show the single-point linear distribution of fatigue loading applied to the blade during the test at NREL. The loads were applied to the blade at the 8.65-m station using dual actuators acting at right angles.

Several practical matters should be pointed out to complete the discussion on the NedWind 25 fatigue test loads. To minimize flap displacements during the test, the load introduction point was moved inboard from the best load station, which would have been at least 1meter further outboard from the 8.65 station. The 8.65 station still allowed the equivalent-damage flap loads to be matched or exceeded over a majority of the in-board blade stations where most of the fatigue damage was expected. Because the loads had to be applied at the same station, the position of the loading was not optimized for both flap and lead-lag directions, therefore we decided to allow the lead-lag loads to drift further from the calculated values while holding the flap loads firm. As shown in Figure 7, this problem was dealt with by forcing the single-point lead-lag test loads through Station 4 at the root flange. This ensured that all stations from Station 4 out to almost Station 9 were tested at or above the design condition in lead-lag.

Another concern was that the test-load apparatus could only apply the loads at one test-load ratio for the entire span; however, each station had a unique $R_{t}$ value. We found that the variations in $R_{t}$ values were small enough that these differences could be introduced into the $M_{\text {min }}$ curve of Figures 6 and 7 without altering the effective damage significantly. We decided that this was a better alternative than forcing the $\mathrm{R}_{\mathrm{t}}$ at all stations to be the same and deviating from the optimum values. The actuator was set up to apply the optimized $R_{t}$ values for station 5 .

\section{NREL TEST SUMMARY}

We conducted two blade fatigue tests consecutively on two NedWind 25 blades. The first test used a singleaxis test-load, combining the flap and lead-lag equivalent-damage test-loads into a single resultant load. The test showed visible blade damage in several areas but no catastrophic failures.

The second test used a two-axis load method, which allowed the individual load components for flap and lead-lag to be applied independently at the optimum load ratios and at a predetermined phase angle.

The two-axis blade results showed the same visible damage as the first test; however, the onset of the 
damage was delayed by more than an order of magnitude in cycles. This is probably due to the higher in-phase loading for the single-axis test rather than blade construction differences. Correspondence with the laboratory at CRES indicates that the same visual damage seen at NREL was also seen at CRES.

A more complete discussion of NREL's SMT program results is given in Reference 1. When this paper was written, the SMT results from the other participating laboratories were not available, so direct comparisons to the fatigue load methods used by other laboratories are not given.

\section{CONCLUSIONS}

This study revealed a simplified method of determining equivalent-damage test loads without any specific knowledge of the test blade structure or geometry. The only inputs were the fatigue-load spectrum and an assumed family of fatigue curves chosen to bound the actual test blade fatigue performance. The method was applied to the NedWind 25 fatigue-load spectrum with good results, particularly in the more critical flap direction.

The method simplifies the process of producing fatigue test loads from a design load spectrum. Unconstrained, the simplified method suggests that for the NedWind 25 spectrum, the S-N slope design condition of $m=10$ is non-conservative, especially for the lead-lag load spectrum. Higher lead-lag test loads are indicated if the $\mathrm{m}=6$ curve is used at the optimum load ratio.

We also illustrated the importance of using a test load ratio that is optimized for the design load spectrum.
This method is adaptable to different fatigue curves and Goodman relationships. Future work should test this method against other design spectrums.

\section{ACKNOWLEDGEMENTS}

The authors wish to thank the contributors who made this project happen. Thanks go to Scott Larwood who ran our NedWind 25 blade testing and contributed his thoughts and comments from beginning to end. We would also like to thank Mike Zuteck, and Jim Richmond for their special skills and insights in helping to develop the test loads. Thanks also go to our SMT colleagues and friends in Europe at RIS $\varnothing$, CRES, Delft, and ECN for inviting us to join the project and accepting our input throughout the project. And finally, thanks to the U.S. Department of Energy for their continued funding support and recognition of structural testing as a valued asset of the wind energy industry.

\section{REFERENCES}

1. Larwood, S. and Musial. W.D., "Comprehensive Testing of NedWind 12 Meter Wind Turbine Blades at NREL," Proceedings $39^{\text {th }}$ AIAA Aerospace Sciences Meeting, Wind Energy Symposium, Reno, Nevada, January 2000.

2. IEC 88/84/CD. Draft IEC 61400-23: Testing of Rotor Blades. September 1998.

3. Mandell, John F. and Samborsky, Daniel D., "DOE/MSU Composite Material Fatigue Database: Test Methods, Materials, and Analysis," Sandia National Laboratories, SAND97-3002, December 1997.

4. Van Grol, H.J., Strength and Fatigue Testing of Large Size Wind Turbine Rotors, ECN Technical Report, ECN-C_95-052, June 1996. 


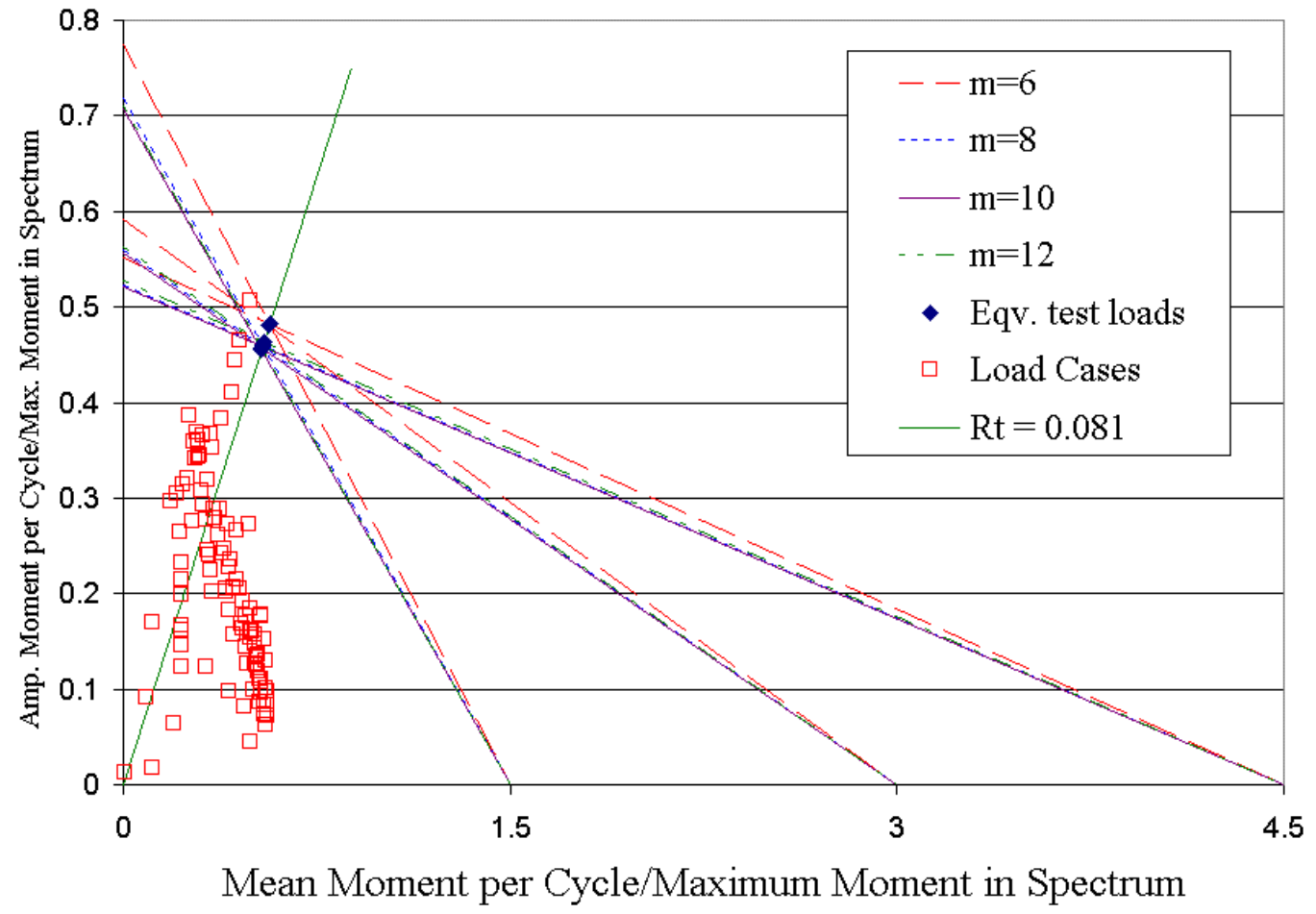

Figure 4. Blade Station 5 flap bending loads and equivalent test loads at $R_{t}=0.081$

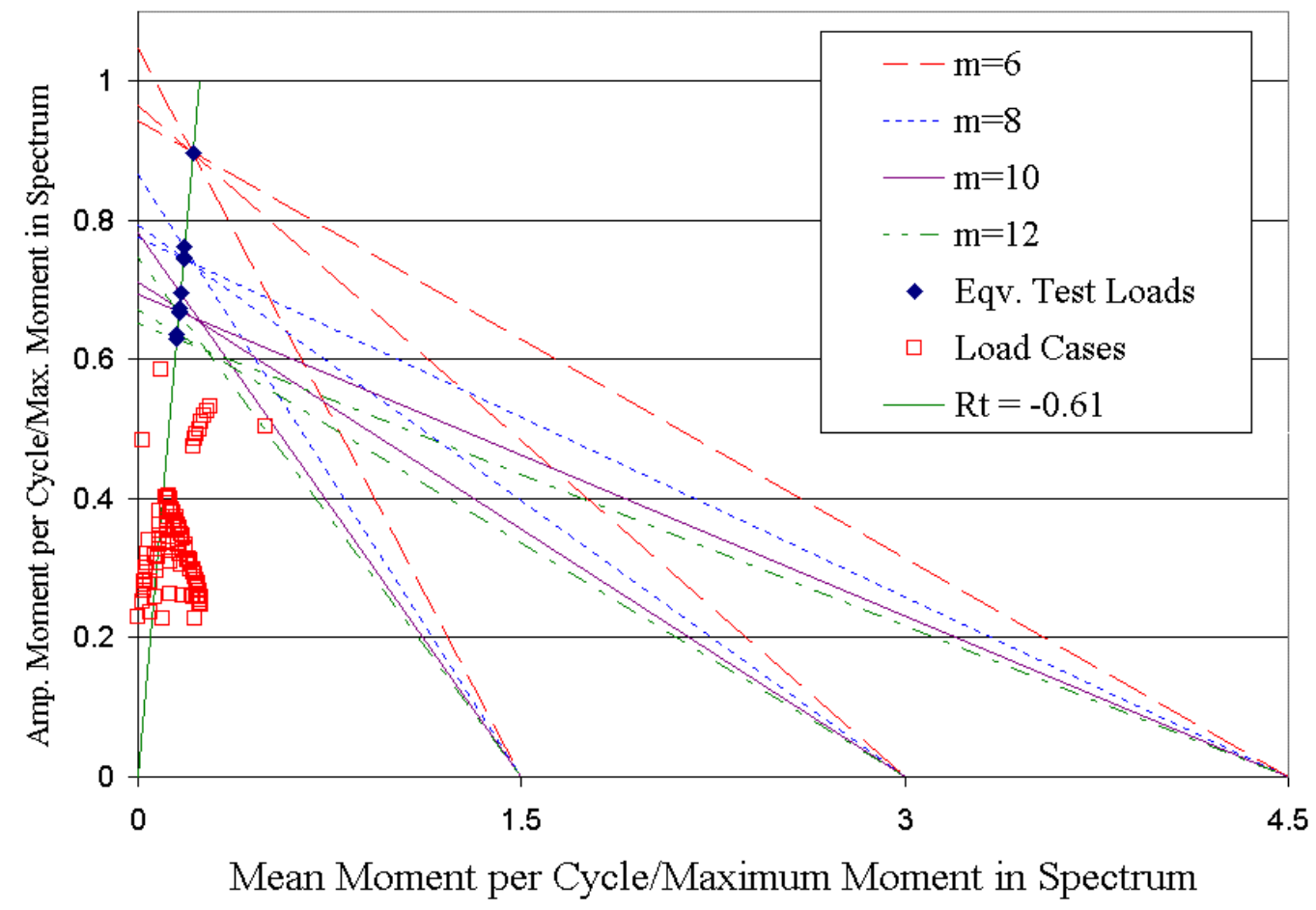

Figure 5. Blade Station 5 lead-lag bending loads and equivalent test loads at $R_{t}=\mathbf{- 0 . 6 1}$ 


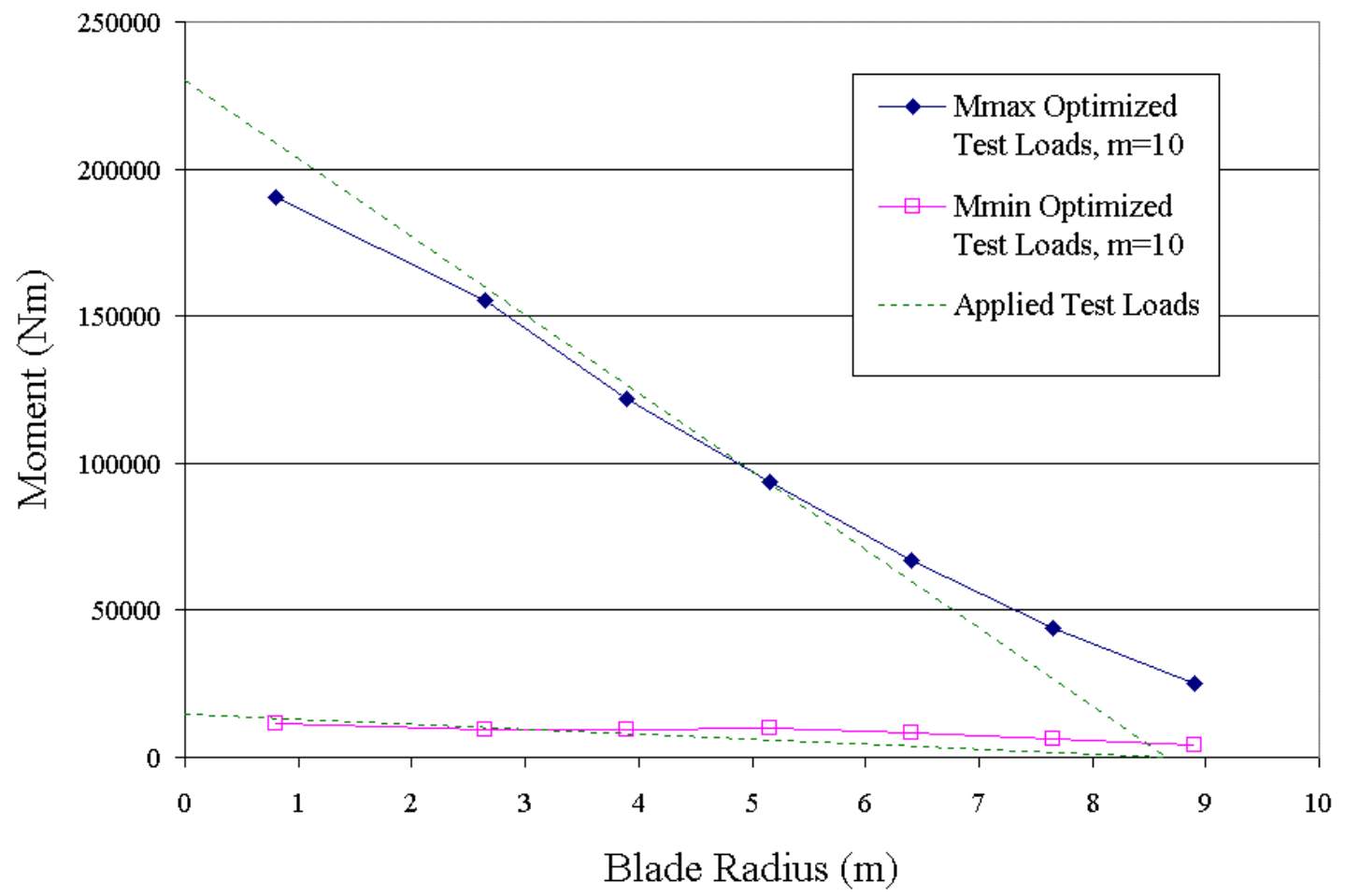

Figure 6. Optimized and applied flap bending test loads along blade span for $\mathbf{m = 1 0}$.

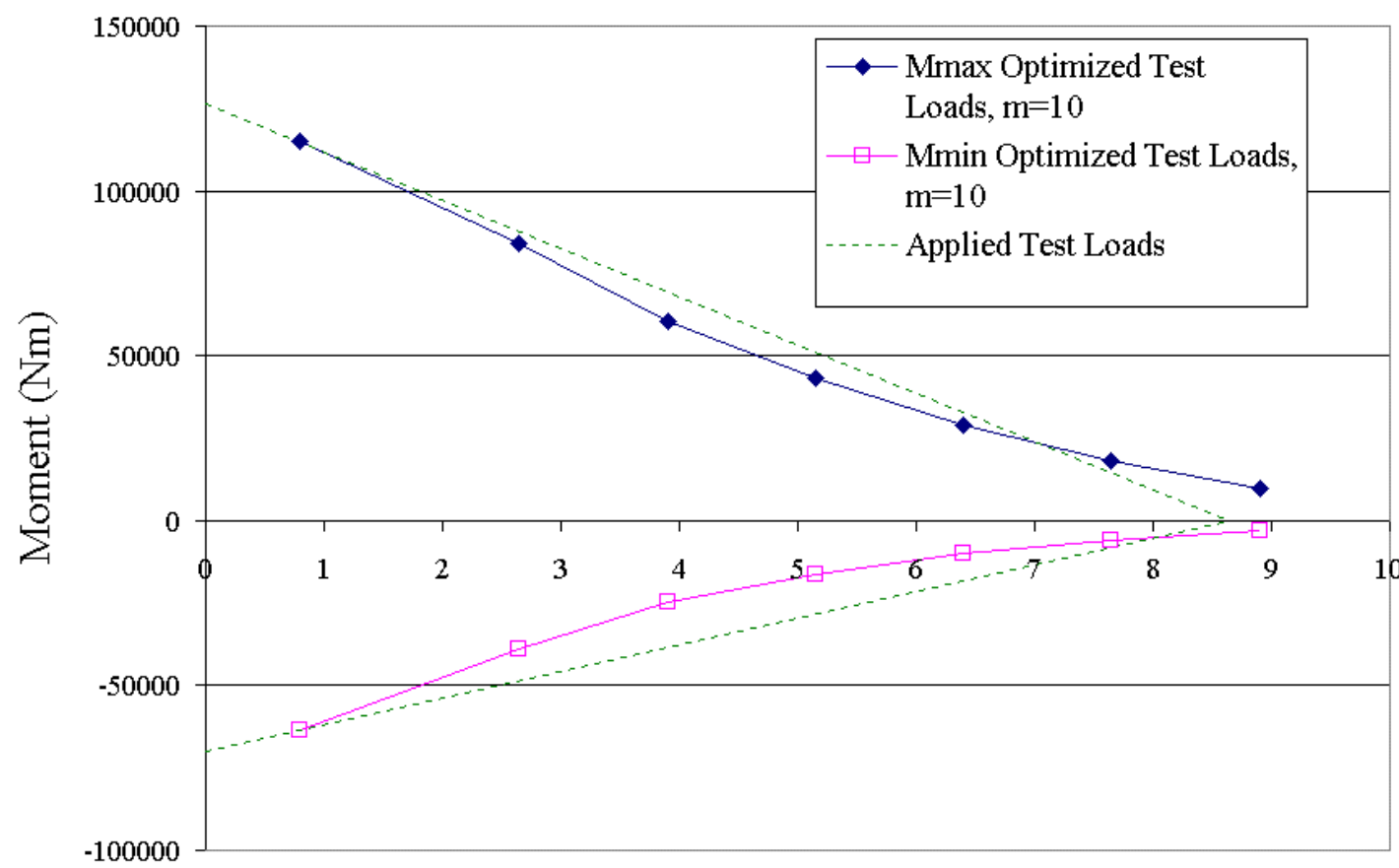

Blade Radius (m)

Figure 7. Optimized and applied lead-lag bending test loads along blade span for $\mathbf{m}=\mathbf{1 0}$. 